\title{
Performance Analysis of BLDC generator Power Maximization Using PI and Fuzzy Logic Controller
}

\author{
Siranthini Balraj ${ }^{1}$ and Anitha Ganesan ${ }^{2}$
}

\author{
${ }^{1}$ Research Scholar and ${ }^{2}$ Associate Professor \\ Division of Avionics, Department of Aerospace Engineering, \\ Madras Institute of technology, Anna University, Chennai, India
}

\begin{abstract}
Brushless DC drives are extensively used in many automotive applications as motor or generator because of its more efficiency, more power density, simplicity of control, and lesser maintenance. This paper deals the power maximization and control of Brushless DC Generator (BLDC) using PI and Fuzzy logic controller (FLC) with hysteresis comparator. Sensorless control of position estimation is employed instead of Hall Effect position sensor where heat effective and costly. The BLDC generator power conversion, when using the conventional uncontrolled rectification methods using diodes, have their own limitations which may not maximize the possible power due to non-optimal current and low power per ampere ratio. This problem is cured using controlled rectifier and suggested to maximize the power generated from the BLDC generator. Traditional PI controller and Fuzzy Logic Controller are applied to control and maintain the DC link output voltage via Hysteresis comparator. Both controller performance is analysed using MATLAB simulation and experimental test verify the results. Key words : BLDC generator, PI controller, Fuzzy logic controller, Hysteresis Comparator, Controlled rectifier
\end{abstract}

\section{Introduction}

Electricity demand is rapidly increasing day by day, however the design and construction of new power plants take a long time. So, independent generators are necessary not only for remote areas, but also for urban areas especially in transportation and automotive applications. Advances in the development of the permanent magnet (PM) machines (motor/generator) in addition to development of fast semiconductor switches and cost-effective OSP processors provide new solutions for industrial applications, electric and hybrid vehicles. Among several kinds of PM generators, the brushless DC (BLDC) generator is the best candidate for improving the power density [1]. As compared with other generators, the BLDC generator has lots of benefits including lightweight, compact design, ease of control and low maintenance due to itself magnetic source [2-3]. With the inherent advantages of the BLDC generator, additional increases in power density can be expected by the advanced control techniques, resulting in considerable reduction of weight and volume [3-7]. In the conventional drive system, generated electrical power is transferred to the DC-side battery through the uncontrolled diode rectifier and loses a great deal of energy as a reactive power. Diode rectification method is simple and cheap, but power per ampere ratio is low because of the distorted waveform. Many advanced control techniques to maximize the power from BLDC generator such as, zero sequence elimination method [3], minimization of torque ripples and joule losses [4], Digital control technique [5], direct power control technique [6] and current control shaping algorithm using hysteresis and PI controller [7] have presented.

The literature survey reveals that the best way to maximize the power from BLDC generator is using active rectifiers. This paper analysis the performance of BLDC generator power maximization using two controllers one is PI controller and another one is Fuzzy logic controller. Both controllers are tested separately with sensorless back EMF detection with Hysteresis comparator. In both analyses Voltage has been taken as the controlling parameter.

This paper is organized as follows, Section 2 presents an analysis of Brushless DC Generator, Section 3 describes the control components 
description for proposed design and requirements, section 5 gives Experimental result and finally last section presents the conclusion.

\section{Analysis of BLDC generator}

Permanent magnet Brushless Generators consist of three phase stator, rotor. Based on the nature of induced voltage in stator it has two types, one is Sinusoidal type (PMSG- Permanent Magnet synchronous Generator) another one is trapezoidal type (BLDCG) . It has $15 \%$ higher power density compared with PMSG. The proposed power maximization circuit using BLDCG is shown in Fig 2.

In general, the Generators are characterized by their back emf constant $\left(\mathrm{K}_{\mathrm{e}}\right)$ and winding resistance (R), the equivalent circuit of BLDC generator is shown in Fig 1. The induced backEMF is given by equation,

$$
\left.\begin{array}{l}
\mathrm{E}_{\mathrm{R}}=\mathrm{R}_{\mathrm{S}} \mathrm{i}_{\mathrm{R}}+\left(\mathrm{L}_{\mathrm{S}^{-}} \mathrm{L}_{\mathrm{M}}\right) \frac{\partial i R}{\partial t}+\mathrm{V}_{\mathrm{R}} \\
\mathrm{E}_{\mathrm{Y}}=\mathrm{R}_{\mathrm{S}} \mathrm{i}_{\mathrm{Y}}+\left(\mathrm{L}_{\mathrm{S}^{-}} \mathrm{L}_{\mathrm{M}}\right) \frac{\partial i Y}{\partial t}+\mathrm{V}_{\mathrm{Y}} \\
\mathrm{E}_{\mathrm{B}}=\mathrm{R}_{\mathrm{S}} \mathrm{i}_{\mathrm{B}}+\left(\mathrm{L}_{\mathrm{S}^{-}} \mathrm{L}_{\mathrm{M}}\right) \frac{\partial i B}{\partial t}+\mathrm{V}_{\mathrm{B}}
\end{array}\right\}
$$

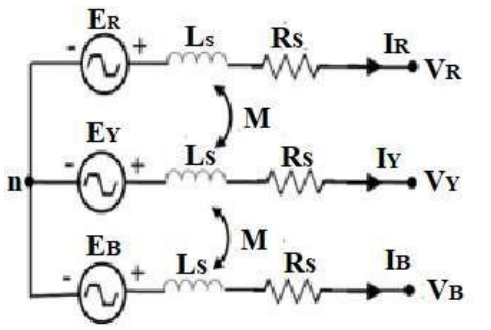

Fig 1. Equivalent Circuit of BLDC

where,

$E_{R}, E_{Y}, E_{B}=$ Back EMF of phase R,Y, and B [V] $\mathrm{i}_{\mathrm{R}}, \mathrm{i}_{\mathrm{Y}}, \mathrm{i}_{\mathrm{B}}=$ Stator current Phase R, Y and B [A] $\mathrm{V}_{\mathrm{R}}, \mathrm{V}_{\mathrm{Y}}, \mathrm{V}_{\mathrm{B}}=$ Terminal voltage of Phase R, Y,B [V] $\mathrm{R}_{\mathrm{S}} \quad=$ Per phase armature resistance $[\Omega]$ $\mathrm{L}_{\mathrm{S}}, \mathrm{L}_{\mathrm{M}}=$ Per phase armature Self, Mutual inductance $[\mathrm{H}]$

Before going into the analysis, some assumptions are presented to simplify it :

The generator is operated within the rated condition, so the generator is not saturated.

- $\mathrm{R}$ and $\mathrm{L}$ values of all the windings are equal.

- Induced Back emf waveform shape is the same for all three phases

- Power semiconductor devices are ideal.
Section 4 is devoted to simulation test and result, In the Three-phase BLDC generator, the average air gap power [7] is obtained using the following equation:

$$
\begin{aligned}
P_{a v g} & =\sum_{k=R} \int\left\{E_{k}(t) i_{k}(t)\right\} d t \\
& =\int\left\{E_{R}(t) i_{R}(t)+E_{Y}(t) i_{Y}(t)+E_{B}(t) i_{B}(t)\right\} d t
\end{aligned}
$$

The induced backEMF and current in all the phases are same as referred in the assumption, so

$$
=(3 / t) \int\left(E_{R}(t) I_{R}(t)\right) d t
$$

Power output from the generator is,

$$
\mathrm{P}_{\text {output }}=\sum_{\mathrm{k}=\mathrm{R}, \mathrm{Y}, \mathrm{B}}(1 / \mathrm{t}) \int_{0}^{T}(\mathrm{Vk}(\mathrm{t}) \mathrm{Ik}(\mathrm{t})) \mathrm{dt}
$$

Substitute equation 1 in 5 then the three phase power is,

$$
\begin{gathered}
\mathrm{P}_{\text {output }}=(3 / t)\left\{\int E_{\mathrm{R}}(\mathrm{t}) \cdot \mathrm{I}_{\mathrm{R}}(\mathrm{t}) \mathrm{dt}-\int R_{S} \mathrm{I}^{2}{ }_{\mathrm{R}}(\mathrm{t}) \mathrm{dt}-\int\right. \\
\left(L\left(\frac{\partial I R}{\partial t}\right) I_{R}(\mathrm{t}) \mathrm{dt}\right\} \\
=(3 / t) \int E_{\mathrm{R}}(\mathrm{t}) \cdot \mathrm{I}_{\mathrm{R}}(\mathrm{t}) \mathrm{dt}-3 \mathrm{R}_{\mathrm{s}} \mathrm{I}_{\mathrm{R}}^{2}(\mathrm{t})-\left(\begin{array}{cc}
3 L s / t
\end{array}\right) \int \\
\mathrm{I} \quad \text { II }
\end{gathered}
$$

In the above equation I part indicates the average power generated in the airgap, II part indicates the stator copper loss and it is constant value so neglected. III part is stator inductor average power will be becoming zero latter. So it is concluded the output power generated from the BLDC is purely depends upon the airgap power. To maximize the output power is related to the airgap power components of induced back emf and phase current.

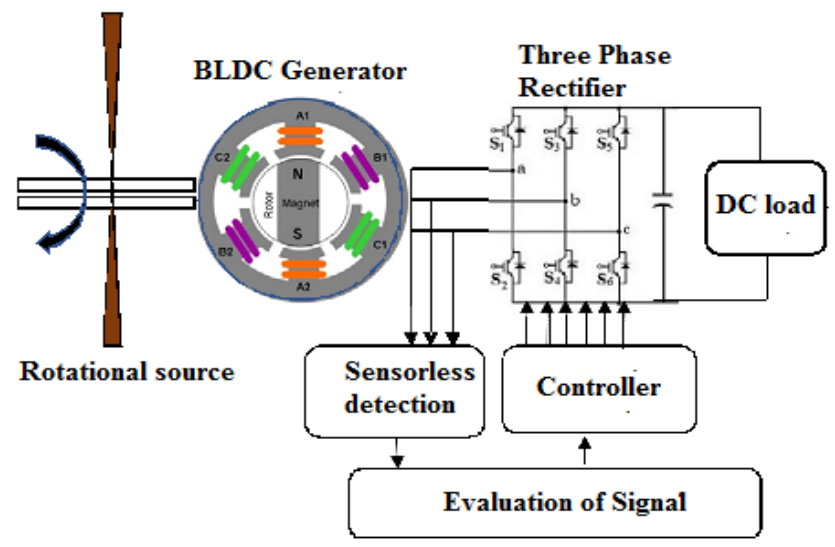

Fig 2. BLDC generator power maximization circuit 


\section{Control Components Description}

\subsection{Sensorless Back EMF detection technique}

The BLDC generator has absence of brushes and electronically commutated. To know or get the accurate ripple free instantaneous torque, information of stator phase current commutation is required. For this purpose, the position sensors like hall sensors, resolvers or absolute position sensors are usually used. Out of these sensors Hall sensors are much uses in most of the application, but it is too costly and temperature sensitive and poor reliability. To rectify this problem many sensorless techniques were proposed [15] and some of them are based on zero crossing point at the three phase line- line voltages or backEMF shown in Fig 3. Whether in any method from the position information only the controller decides the suitable pair of switches i.e transistors (S1 to S6) which must be driven to open or conduct. The required details of rotor position information can be easily retrieved via sensorless backEMF method and moreover this method does not need mechanical components and chosen for this system.

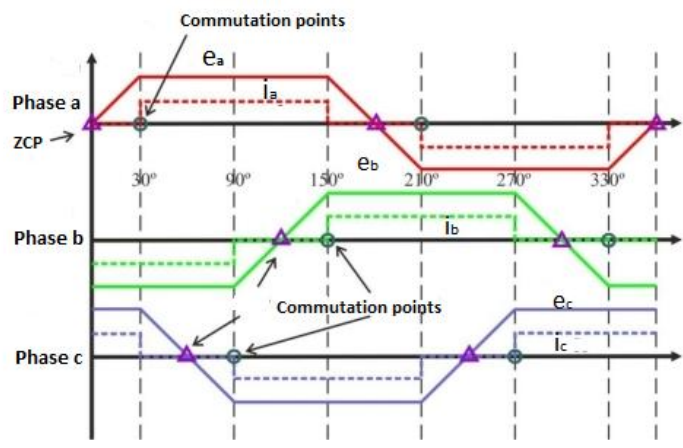

Fig. 3: Back EMF Zero cross detection

\subsection{Hysteresis Comparator}

In this method of voltage control, there are two bands limits have fixed above and under the reference voltage. If the difference between the reference and converter voltage reaches to the upper (lower) limit, the voltage is forced to decrease (increase), depends upon this signal the logic gates creates the gate pulses is shown in Fig 4. The Hysteresis comparator uses two different threshold voltages namely, upper $\left(\mathrm{V}_{\mathrm{ThH}}\right)$ and lower threshold $\left(\mathrm{V}_{\mathrm{ThL}}\right)$ values to decide the exact output $\left(\mathrm{V}_{0}\right)$ The input signal exceeds the upper threshold; the output is transition low $\left(\mathrm{V}_{\mathrm{oL}}\right)$ or below the lower threshold the output is transition high $\left(\mathrm{V}_{\mathrm{oH}}\right)$ and therefore getting the exact controlled output switching gate pulses. The three phase output signals like $Z_{R}, Z_{Y}, Z_{B}$ are combined to form logical equations and gate signals(S1 -S6) in Truth table 1. Each commutation signal has 60- degree phase difference. Advantages of this method are it is quite simple method based on the use of a feedback loop consisting solely of voltages also it is having the ability to control shorter on-time, and high noise tolerance. It also reduces the ripples in considerable amount where having the benefit of maximize the output power. To control the DC link output voltage at a desired value and to prevent it from the fluctuation of load changes is important. PI and fuzzy controllers is employed to maintain constant DC link voltage.

Table 1: Truth Table

\begin{tabular}{|l|l|l|l|l|l|l|l|l|}
\hline ZR & ZY & ZB & S1 & S6 & S3 & S4 & S5 & S2 \\
\hline 0 & 0 & 0 & 0 & 0 & 0 & 0 & 0 & 0 \\
\hline 0 & 0 & 1 & 0 & 0 & 1 & 0 & 0 & 1 \\
\hline 0 & 1 & 0 & 1 & 0 & 0 & 1 & 0 & 0 \\
\hline 0 & 1 & 1 & 1 & 0 & 0 & 0 & 0 & 1 \\
\hline 1 & 0 & 0 & 0 & 1 & 0 & 0 & 1 & 0 \\
\hline 1 & 0 & 1 & 0 & 1 & 1 & 0 & 0 & 0 \\
\hline 1 & 1 & 0 & 0 & 0 & 0 & 1 & 1 & 0 \\
\hline 1 & 1 & 1 & 0 & 0 & 0 & 0 & 0 & 0 \\
\hline
\end{tabular}

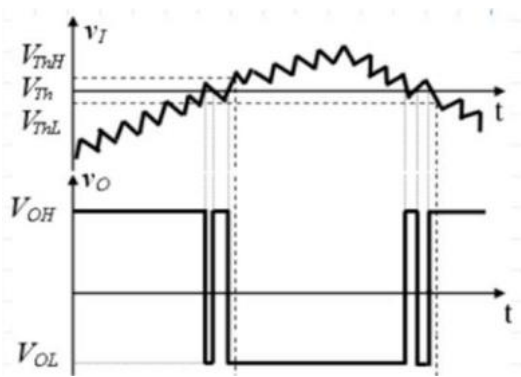

Fig. 4: Hysteresis comparator

\subsection{PI controller}

To control the DC link output voltage at a desired value and to prevent it from the fluctuation of load changes is essential. PI controller is employed to maintain constant DC link voltage. PI controllers consist of a proportional gain $\mathrm{K}_{\mathrm{p}}$ that produces an output proportional to the input error and an integral gain $K_{I}$ to make the study state error zero for a step 
change in the input. Proper selection of $\mathrm{K}_{\mathrm{p}}$ and $\mathrm{K}_{\mathrm{I}}$ makes the system gets minimum error. The functional block diagram of PI controller is shown in the Fig 5.

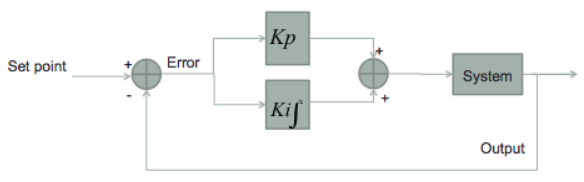

Fig. 5: Basic Design of PI controller

\subsection{Fuzzy logic controller}

In general, the input of the FLC is , error value (e) and changes in error $(\Delta \mathrm{e})$. The main parts of the FLC include: Fuzzification, System inference, Rule base and Defuzzification. The block diagram of the FLC is shown in Fig 6.

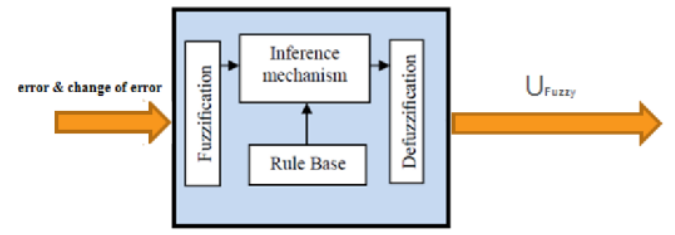

Fig. 6: Block diagram of fuzzy logic controller

The value of error and changes in error obtained from feedback of DC Voltage from its DC output link. The parameter either voltage, current or power which needs to be controlled that one taken as feed back to the controller to control the system. Here voltage is taken as a controlling parameter. The input variable of the FLC are the DC link voltage error and the output of the FLC are the minimum error output . The triangular membership functions are taken for the FLC to make it for easier computation. Three membership fuzzy sets are taken for this system, Negative small(NS), Zero(Z), Positive Small (PS) is defined describe the linguistic variable.

\section{Simulation result}

To Design the BLDC generator model in simulation the design parameters has calculated and presented in the Table 2: The simulation studies were carried out using MATLAB /

Simulink ode23dp solver.
Table 2: BLDC generator simulation parameters

\begin{tabular}{|c|c|c|}
\hline QUANTITY & VALUE & UNIT \\
\hline Resistance & 2.9 & $\Omega$ \\
\hline Inductance & 0.66 & $\mathrm{mH}$ \\
\hline Speed & 5400 & $\mathrm{Rpm}$ \\
\hline $\begin{array}{c}\text { Torque constant } \\
(\mathrm{Kt})\end{array}$ & 0.0054 & $\mathrm{Nm} / \mathrm{A}$ \\
\hline Inertia $(\mathrm{J})$ & $1.61 \mathrm{E}-06$ & $\mathrm{Kg} / \mathrm{m}^{2}$ \\
\hline Emf constant $\left(\mathrm{K}_{\mathrm{e}}\right)$ & 0.01257 & $\mathrm{~V} / \mathrm{rad} / \mathrm{s}$ \\
\hline
\end{tabular}

The BLDC generator simulink model has been developed using the above mentioned parameters and the whole proposed simulation model for PI controller and Fuzzy controller in Fig.7, Hysteresis comparator model in Fig 8 , Fuzzy controller model and design in Fig 9 (a), (b) is presented. The control components to maximize the power from the BLDC generator are induced backEMF and Phase current in the stator winding. In which phase the backEMF is induced is measured by using the open phase, because in BLDC at each phase only two phases are energised and doing conduction, the Third phase at that time will be in open. Moreover, if the losses or other voltage drops are negligible the Stator phase voltage is almost equal to the backEMF. The measured backEMF is multiplied by the error signal given by the controllers. This evaluated signal is sent to the hysteresis comparator where the limit values are already prefixed. The comparator compare the evaluated signal and generate the gate signal by using the logic gates.

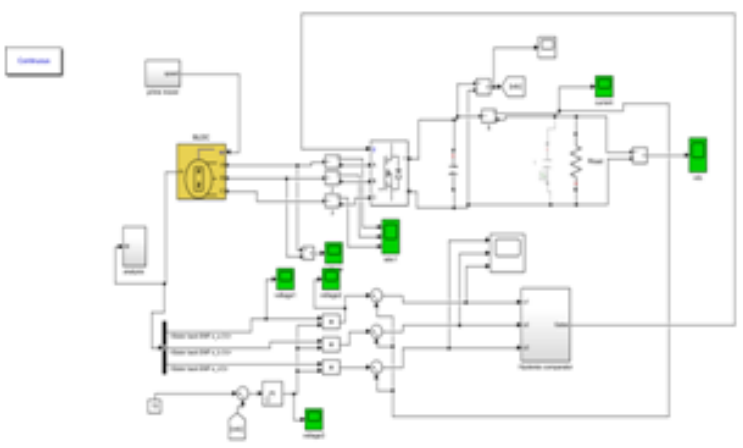

(a) 


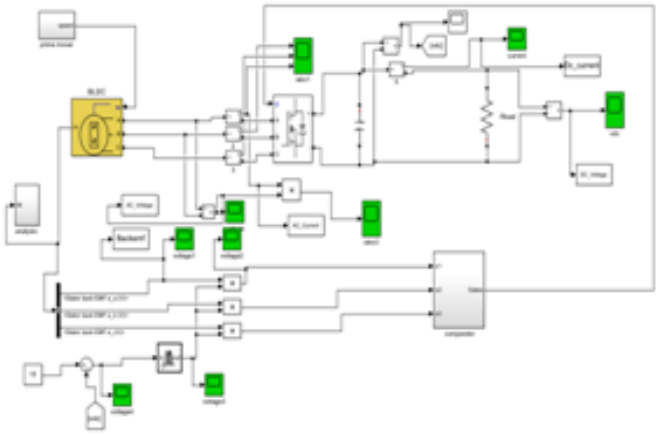

(b)

Fig. 7: Proposed Simulink Model (a) PI controller (b) Fuzzy Controller

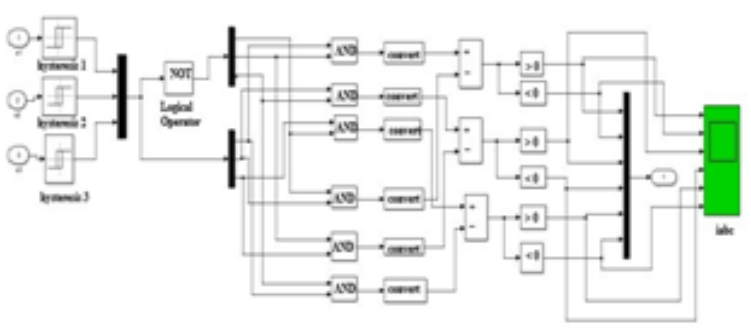

Fig. 8 : Hysteresis Comparator with logic gate circuit

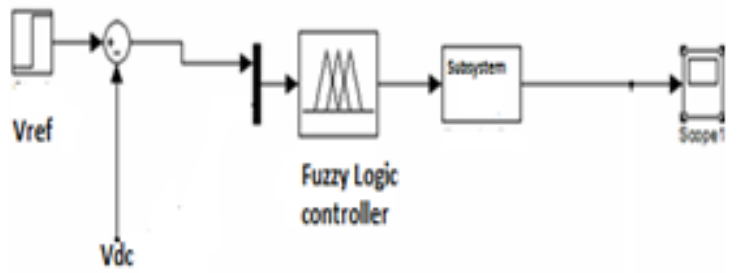

(a)

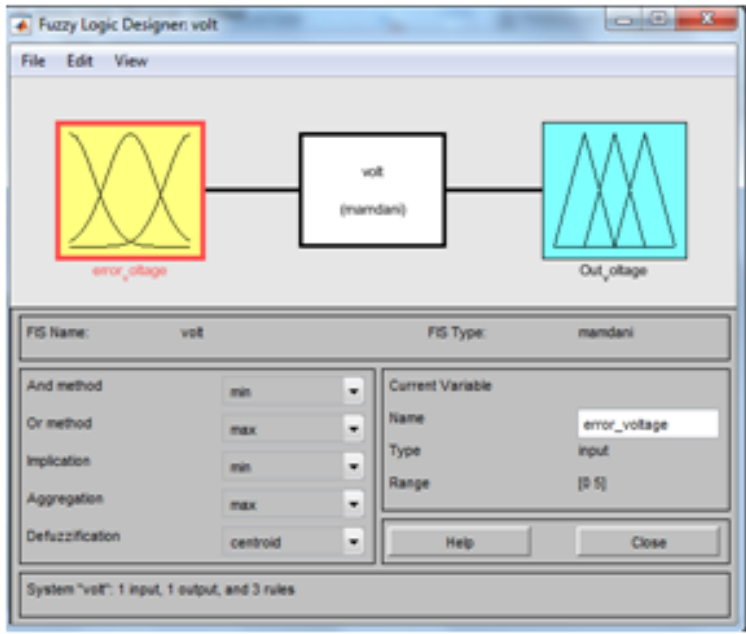

$\begin{array}{lll}\text { (b) Fig.9: (a) FLC Model } & \text { (b) FLC Design }\end{array}$

\subsection{DC link voltage tracking and regulation}

At the time of simulation, the maximum speed of $10,000 \mathrm{rpm}$ to minimum $1000 \mathrm{rpm}$ was used to test the BLDC generator. Using the controller the error voltage has minimized, where PI controller used its own mathematical design, but FLC used its logic methods without any mathematical equation. The Employed PI controller with its $\mathrm{Kp}, \mathrm{Ki}$ coefficients are followed the voltage changes and gives good respond to the load and torque changes. So the error has reduced or near to Zero then the output power gets maximized. At 5400rpm the output of the BLDC generator three phase Stator current, stator voltage, Induced backEMF and torque signal is shown in figure 10 (a,b,c,d,e,f), The PI and fuzzy controller simulation output results presented in figure $11(\mathrm{a}, \mathrm{b})$.

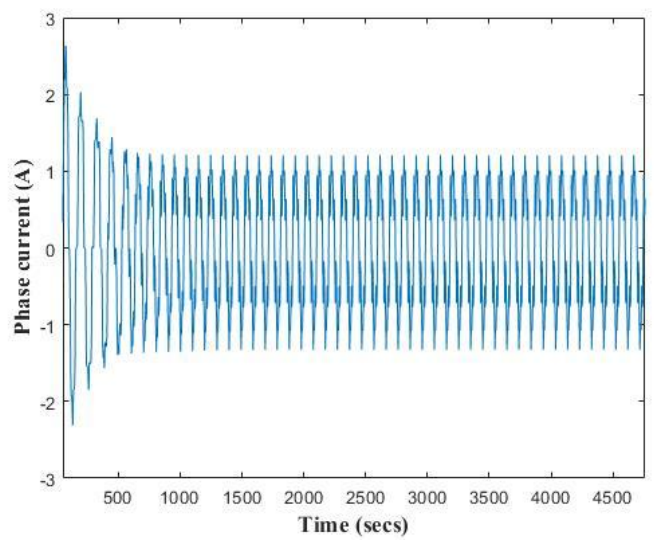

(a)

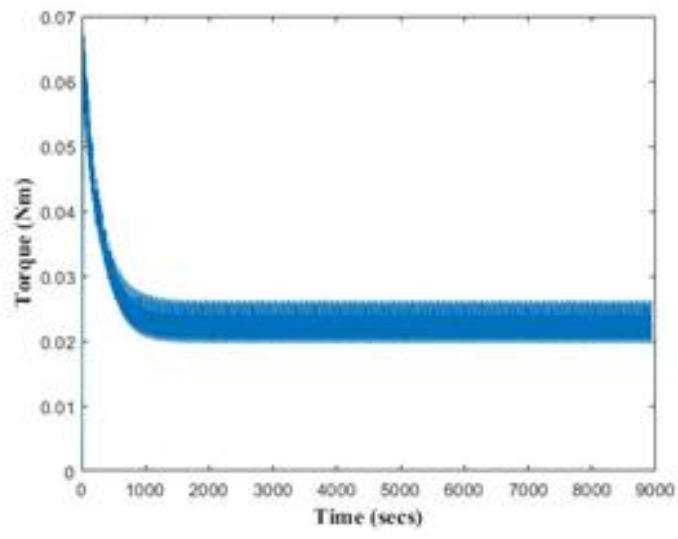

(b) 


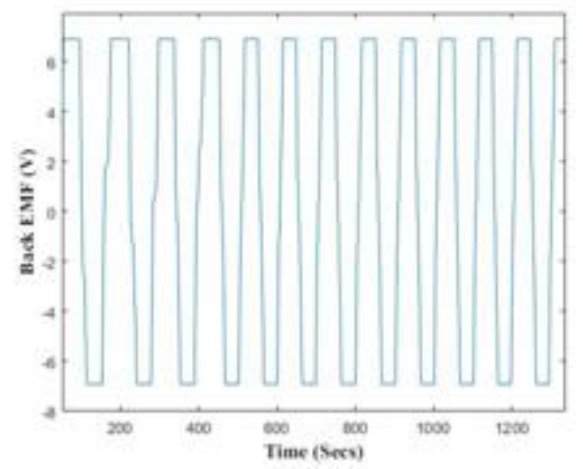

(c)

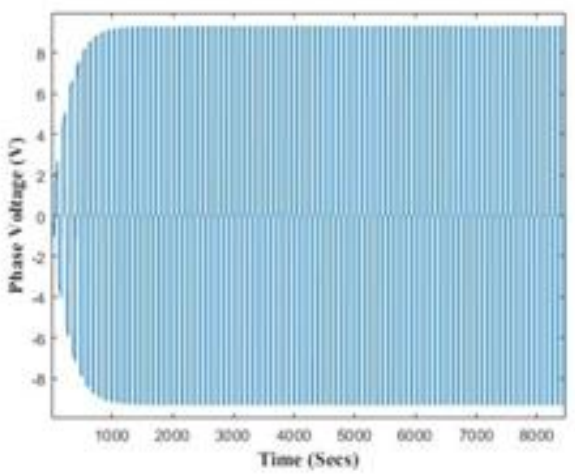

(d)

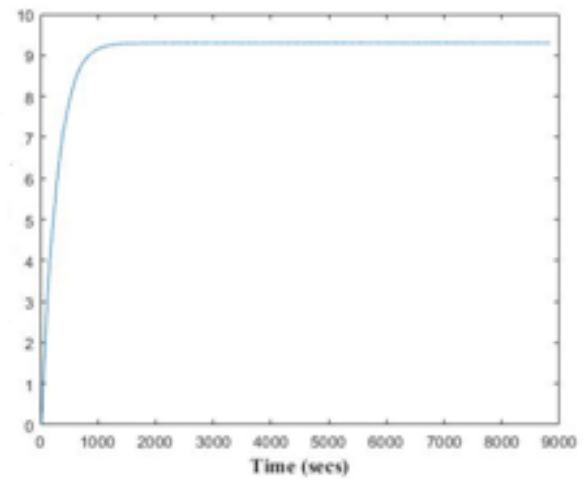

(e)

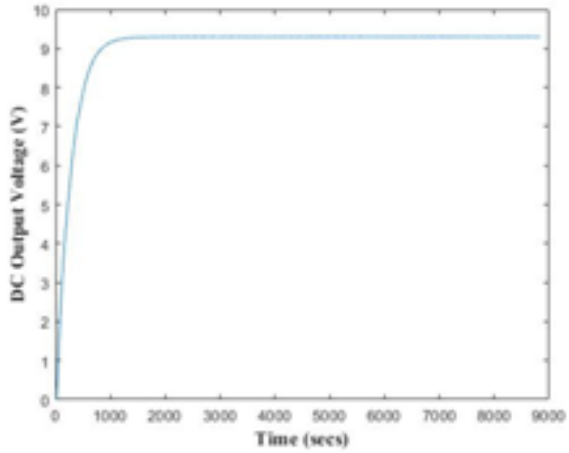

(f)

Figure 10 : BLDC generator simulation outputs
(a) Stator Phase current (A)
(b) Torque (Nm)
(c) induced BackEMF (V)
(d) Stator phase Voltage (V)
(e) DC output current (mA)
(f) DC output Voltage (V)

The output DC power by input Ac power gives the efficiency of the system and for both controllers the efficiency is calculated and tabulated in Table 3. It seems ,from the Fig 11, for low speed the output DC link power control almost same for the both controllers, when speed is increased beyond 5400 RPM , Fuzzy controller gives more DC power then the PI controller. But the overall efficiency is calculated using its input power measurement yields that PI controller gives better efficiency then the Fuzzy logic Controller. Both controllers are not tuned and the current of the BLDC generator not taken into consideration of controllable parameter for power maximization.

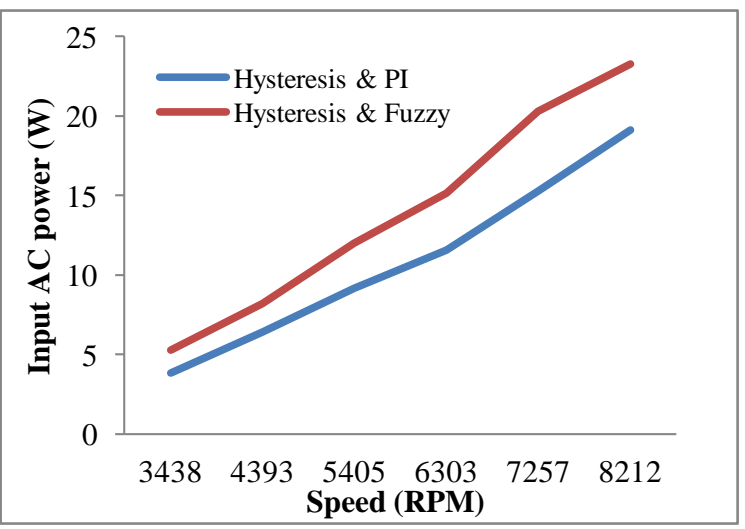

(a) 


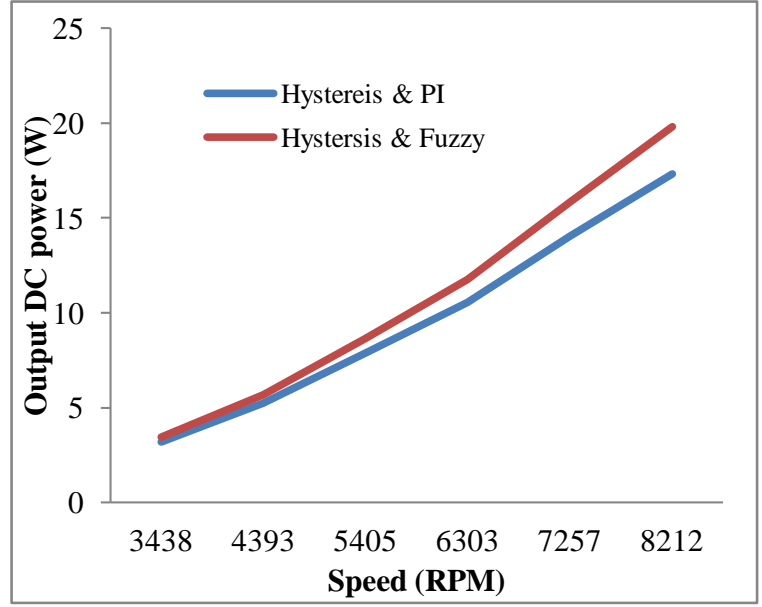

(b)

Figure 11: (a) Input AC Power Vs Speed

(b) Output Power Vs Speed

Table 3 : Overall Efficiency

\begin{tabular}{|c|c|}
\hline Techniques & Efficiency $(\%)$ \\
\hline $\begin{array}{c}\text { Hysteresis \& PI } \\
\text { controller }\end{array}$ & 90.38 \\
\hline $\begin{array}{c}\text { Hysteresis \& Fuzzy } \\
\text { controller }\end{array}$ & 85.16 \\
\hline
\end{tabular}

\section{Experimental Results}

Based upon the simulation result the hardware setup has been developed for Hysteresis comparator with PI controller and results are analysed and compared with the simulation result. Initially, before going to test the proposed system the BLDC generator is tested to analyze its performance under various speeds. The maximum speed has given as 10,000 rpm via Arduino controller through a program to motor and the BLDC generator is mounted above the motor. The corresponding maximum phase to phase $\mathrm{AC}$ voltage and the current output waveform and results were taken using Digital storage oscilloscope is shown in Fig 12. a, b. The speed of the generator is tested using the speed encoder with Arduino controller. PIC16F877A controller was employed for controlling the action of all controls including Hysteresis and PI control via program. The comparison of simulation and hardware for PI controller with hysteresis comparator was tabulated in Table 4.

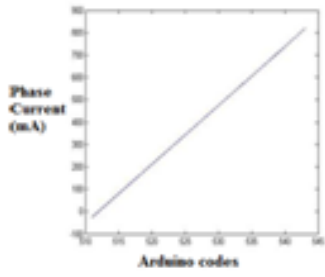

(a)

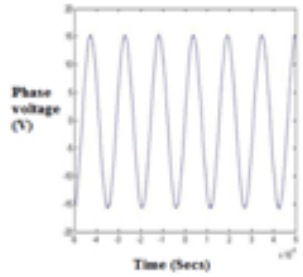

(b)
Fig. 12: Single Harvester Test output

(a) Max.Current (b) Max. Voltage at max.Speed

Hardware results proves and validate the simulation results of Power maximization circuit. The simulation result is higher than the experimental result, because generator losses and time delay are not considered in the simulation, and current, induced voltage shape could be possible to keep in-phase using simulation.

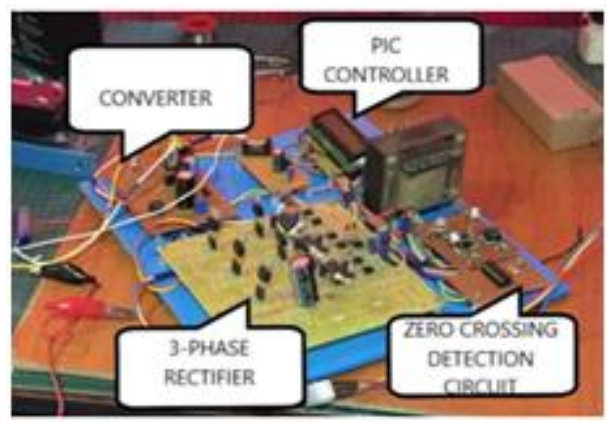

(a)

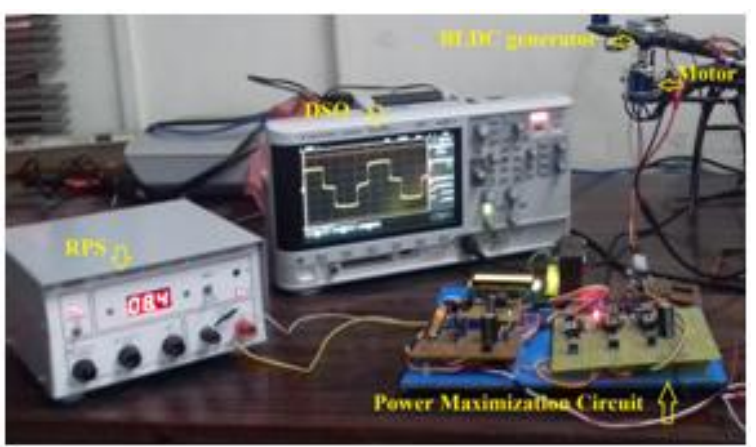

(b)

Fig. 13: Hardware test

(a) Power maximization circuit

(b) Whole Test setup 
Table 4 : Result comparison

\begin{tabular}{|l|r|r|}
\hline Parameter & \multicolumn{1}{|l|}{ Simulation } & \multicolumn{2}{|l|}{ Hardware } \\
\hline Speed [rpm] & 5400 & 5400 \\
\hline $\begin{array}{l}\text { Load } \\
\text { Resistance } \Omega]\end{array}$ & 100 & 100 \\
\hline $\begin{array}{l}\text { Output DC } \\
\text { Voltage[V] }\end{array}$ & 13 & 0.1 \\
\hline $\begin{array}{l}\text { Output DC } \\
\text { Current [A] }\end{array}$ & 0.13 & 1.01 \\
\hline $\begin{array}{l}\text { Output Power } \\
\text { [W] }\end{array}$ & 1.69 & 0.1 \\
\hline
\end{tabular}

\section{Conclusion}

Two types of control techniques for maximizing the power from the BLDC generator have been presented. Simulations were performed for both controllers i.e PI and Fuzzy logic controller using sensorless backEMF detection with Hysteresis comparator. The both controllers performed well and power per amps and efficiency is achieved. Here Voltage has taken as the controlling parameter. Compared with simulation time, error detection range and computational time, Fuzzy logic controller DC power output result seems better than the PI controller, but overall efficiency is higher for PI controller. Based upon this result hardware was built and validate the simulation result.

\section{References}

1. Lee, H.-W., Kim, T.-H., and Ehsani, M. "Power density maximization of the brushless DC generator', published on IEEE Pro Conf. IECON'03, pp. 2162-2166, Nov 2003.

2. H-W Lee, T-H Kim and Ehsani "Maximum power throughput in the multiphase brushless DC Generators", IEEE Electric power applications., vol.152, No.3, May 2005.

3. Hyung-Woo Lee, Tae-Hyung Kim, and Mehrdad Ehsani, "Practical Control for Improving Power Density and Efficiency of the BLDC Generator" IEEE transactions on power electronics, vol. 20, no. 1, Jan 2005.

4. G. Gatto, 1. Marongiu, A. Perfetto, and A. Serpi, "Brushless DC generator controlled by predictive algorithm," published in IEEE International conf. on clean electrical power, pp.727-732, Aug 2009.

5. Nikola Milivojevic, Mahesh Krishnamurthy, Ali Emadi, and Igor Stamenkovic, "Theory and Implementation of a Simple Digital Control Strategy for Brushless DC Generators "IEEE transactions on power electronics, vol. 26, no. 11, Nov 2011.

6. Halvaei Niasar, A., Majid Moazzemi, "Design and Implementation of Direct Power Control System for Brushless DC Generator in Standalone DC Applications", Taylor \& Francis, Electric Power components and systems, vol.45, no.7, pp 752-762, May 2017.

7. Halvaei Niasar, A.,Sabbaghean, A. "Design and implementation of a low-cost maximization power conversion system for brushless DC generator", Elsevier Ain Shams Engineering Journal, vol. 8, issue 4, pp. 571-580, Dec 2017.

8. T. W. Chun, Q.-V. Tran, H.-H. Lee, and H.G. Kim, "Sensorless control of BLDC motor drive for an automotive fuel pump using a hysteresis

comparator,'IEEETrans.PowerElectron.,vol. 29,no.3,pp.1382-1391, Mar. 2014.

9. Salinamakki Gurumurthy, Vivek Agarwal, Archana Sharma "Optimal energy harvesting from a highspeed brushless DC generator-based flywheel energy storage system "IET electric power applications, vol.7, issue.9, pp 693-700, Aug 2013

10. Yu Wang, Zhuoran Zhang, Li Yu, and Yuting Wang "Investigation of a VariableSpeed Operating Doubly Salient Brushless Generator for Automobile On- Board Generation Application "IEEE transactions on magnetics, vol. 51, no. 11, November 2015.

11. K. T. Chau, C. C. Chan, and Chunhua Liu, "Overview of Permanent-Magnet Brushless Drives for Electric and Hybrid Electric Vehicles", IEEE transactions on industrial electronics, vol. 55, no. 6, June 2008.

12. M.H. Rashid, "Power Electronics Handbook: Devices, Circuits, and 
Applications", Academic Press, Vol. 19, pp.525-530, 2006

13. S.R. Shankapal, Parikshith Mallya, Jayashree Shivkumar, and N. Venkateswaran "design Analysis of Brushless direct current Generator", Defence Science Journal, Vol. 67, No. 4, pp. 437-442, DOI : 10.14429/dsj.67.11546 2017.

14. R. Manikandan, R. Thenmozhi, V.Vasudhevan, P. Shobanaji, S. Sharmila and E. S. Swetha "online diagnostics and data capturing on a brushless dc generator", ARPN Journal of Engineering and Applied Sciences VOL. 11, NO. 17, ISSN 18196608, 2016 .

15. Bilal Akin and Manish Bhardwaj "Sensorless Trapezoidal Control of BLDC Motors", , Application report Texas Instrument ,SPRABQ7A-July 2013Revised September 2015. 